\title{
Review \\ Recent Tendencies in the Use of Optimization Techniques in Geotechnics: A Review
}

\author{
Djamalddine Boumezerane
}

check for updates

Citation: Boumezerane, D. Recent Tendencies in the Use of Optimization Techniques in Geotechnics: A Review. Geotechnics 2022, 2, 114-132. https://doi.org/ 10.3390/geotechnics2010005

Academic Editor: George Mylonakis

Received: 29 November 2021

Accepted: 20 January 2022

Published: 22 January 2022

Publisher's Note: MDPI stays neutral with regard to jurisdictional claims in published maps and institutional affiliations.

Copyright: (c) 2022 by the author Licensee MDPI, Basel, Switzerland. This article is an open access article distributed under the terms and conditions of the Creative Commons Attribution (CC BY) license (https:/ / creativecommons.org/licenses/by/ $4.0 /)$.
Engineering Division, School of Computing Engineering and Physical Sciences, University of the West of Scotland, Paisley, High Street, Glasgow G72 0LH, UK; Djamalddine.boumezeranel@uws.ac.uk; Tel.: +44-141-848-3513

\begin{abstract}
The use of optimization methods in geotechnics dates back to the 1950s. They were used in slope stability analysis (Bishop) and evolved to a wide range of applications in ground engineering. We present here a non-exhaustive review of recent publications that relate to the use of different optimization techniques in geotechnical engineering. Metaheuristic methods are present in almost all the problems in geotechnics that deal with optimization. In a number of cases, they are used as single techniques, in others in combination with other approaches, and in a number of situations as hybrids. Different results are discussed showing the advantages and issues of the techniques used. Computational time is one of the issues, as well as the assumptions those methods are based on. The article can be read as an update regarding the recent tendencies in the use of optimization techniques in geotechnics.
\end{abstract}

Keywords: optimization; geotechnical engineering; metaheuristic methods; deterministic methods; slope stability; foundations; soil properties

\section{Introduction}

When we talk about optimization in geotechnics that includes uncertainty, sensitivity and robustness analysis [1]. If we focus on optimization per se, that could be defined as "the mathematical-based selection of the best fitting objects in respect to defined criteria".

Optimization leads to the maximizing or minimizing of functions by choosing input values or functions from a certain parameter set or range. Different deterministic and stochastic optimization schemes are available. Popular deterministic approaches are response surface methods, gradient-based strategies and others. On the other hand, typical stochastic approaches are widespread and they include: evolutionary algorithms, neural network approaches, particle swarm algorithms or the fuzzy logic theory-based methods. Optimization can be mono-objective where an optimum is searched for one function or multi-objective, where an optimum is searched not only for one parameter or function, but for several and sometimes also contradictory objective functions (Pareto optimization).

In this paper we present a review of most of the recently used methods for optimization in geotechnics, grouped within three main domains: foundations, slope stability, soil properties and investigations. We point to the main optimization methods and how they are used for solving geotechnical problems. A summary is given to show in statistical terms the use of metaheuristic and deterministic methods.

\section{Optimization Methods for Foundations}

Smith et al. [2] in a work on the use of discontinuity layout optimization (DLO) showed application of this technique as an alternative to traditional analysis techniques (Figure 1). The method coined DLO originates to a work by Smith and Gilbert [3] where it was applied to optimization of plane plasticity problems. It is formulated in terms of discontinuities and generally set in four stages: (1) starting problem with the applied surcharges on a given soil. (2) Discretizing of soil nodes. (3) Interconnection nodes with potential discontinuities. (4) 
Identification of critical subset of potential discontinuities using optimization. The method provides an efficient tool for dealing automatically with the traditional "upper bound" hand analysis.
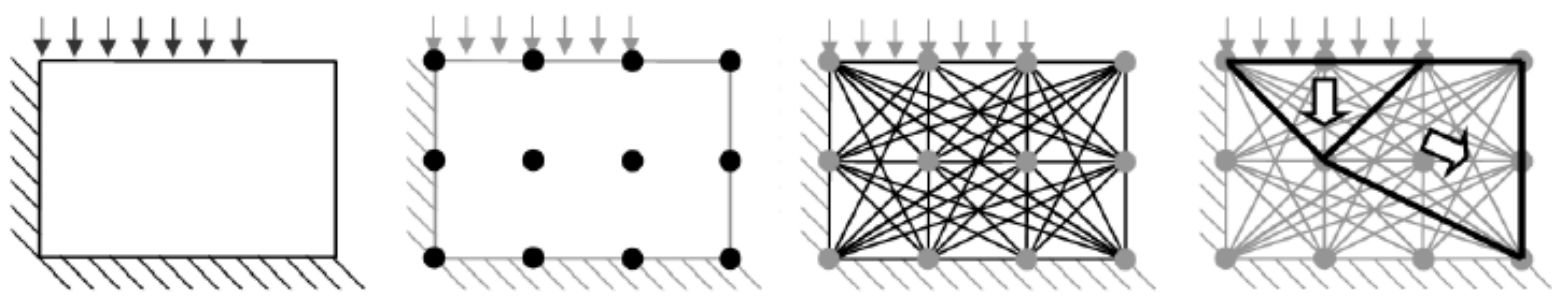

Figure 1. Stages in discontinuity layout optimization (DLO) procedure.

The DLO method was also used by Gilbert et al. [4] in optimization of geotechnical limit analysis problems such as retaining walls or surcharge near a vertical cut. A free access Matlab script was also provided for calculations, and it shows that the basic procedure can be implemented easily.

DLO presents a good tool for the analysis and design of reinforced slopes. Gonzales and Smith [5] presented a modified formulation of DLO for determining the optimal layout of reinforcement for any given earthwork geometry. The proposed approach is able to find the minimum tensile strength of the reinforcing material and optimal layout required for the stability of the system for a given initial design domain. According to the authors the proposed procedure has been shown to generate similar but slightly more efficient results compared to the conventional approach given in the code of practice HA 68/94.

In a report, Konietzky et al. [1] described optimization of a geotechnical problem including uncertainty, sensitivity and robustness analysis. The paper gives a general overview on development of a model for use in rock mechanics. A finite difference model of the commercial code FLAC was used for the purpose of optimization of a rock mechanical problem of roof anchorage. The interest of the study was in the combination of sensitivity and optimization analysis. The basic strategy of solving rock mechanical problems by using optimization schemes consists of two steps: sensitivity analysis first, followed by optimization. Sensitivity analysis allows finding which input parameters are relevant for the considered problem. Unimportant parameters are skipped and optimization analysis is made easier to perform.

Energy piles gained growing interest in the last few years. Alberdi-Pagola et al. [6] applied a validated approach for sizing and optimization of an energy pile foundation. Semi-empirical multiple pile g-functions yield reliable estimates of fluid temperatures for relatively small, irregular pile arrays. G-functions are dimensionless curves of the change in temperature in the ground over time from applying a thermal load on the pile. The used pile g-functions were derived from 3D temperature modelling of single energy piles for different pile length to diameter ratios (aspect ratio), which yield pile and soil temperatures at specified radial distances. The principle of the approach is to choose an energy pile pattern from the predefined grid of foundation piles and estimate the corresponding fluid temperatures using the multiple pile g-functions. The pattern is then adjusted until the desired temperatures are achieved while honouring the thermal requirements of the building. The optimization is based on providing the energy pile arrangement that maximises the pile spacing, given the structural constraints. The optimization scheme accepts as input the coordinates of the foundation piles, the number of required energy piles and minimum initial pile spacing. From the results obtained, the authors concluded that the multiple pile g-functions yield reliable average fluid temperatures when compared to corresponding observed temperatures during heat extraction.

Optimization methods evolved and different approaches were applied at one moment or the other. Probabilistic approaches were widely used to find the optimal safety factor of a slope given specific soil and loading conditions. Recently, the ant colony algorithm 
was used to optimize slope stability analysis applied to an embankment failure in India by Mishra et al. [7]. The authors used $\mathrm{ACO}_{\mathrm{R}}$ known as an extended continuous ant colony optimization capable of solving problems in the continuous domain. The minimum safety factor is identified using $\mathrm{ACO}_{\mathrm{R}}$ with control parameters varying continuously. In their study, the authors represented a slip surface by a set of $N+1$ decision variables; $x 1, \sigma 1$, $\ldots, \sigma \mathrm{N}-1, \mathrm{xN}+1$. For a $\mathrm{N}+1$ dimensional continuous problem, where an archive of $\mathrm{k}$ solutions is constructed. Each solution in the archive contains the value of $\mathrm{N}+1$ variables used to construct a generic trial slip surface and the factor of safety associated with it. The mathematical construction of the method is demanding. The approach was applied on an embankment failure to show the capabilities of $\mathrm{ACO}_{\mathrm{R}}$. The effect of geogrids and pore water pressure in the embankment was not considered in the analysis for simplification. The authors argued on the performance of the $A C \mathrm{O}_{\mathrm{R}}$ method against other approaches such as GA (genetic algorithms), PSO (particle swarm optimization), and ABC discrete (artificial bee colony) [8-10].

Pile groups are still a challenge for geotechnical engineering, as they need to be optimized for each situation. The soil parameters are always varying from one place to the other. In a recent article, Alhashmi et al. [11] used a reliability method based on binomial systems to optimize the calibration of resistance factor in redundant pile groups. The application of binomial system-reliability is challenged by the need to determine a framework for calculating a key input variable related to the maximum number of defective piles " $\mathrm{m}$ " a pile group can have without collapsing under applied loads (Figure 2). The approach is recent in geotechnics and it permits, when combined with finite element analysis, optimization of the calibration of pile resistance factors for gravity-loaded pile groups in sand.

5 Piles

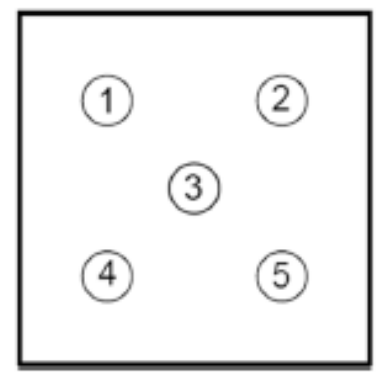

7 Piles

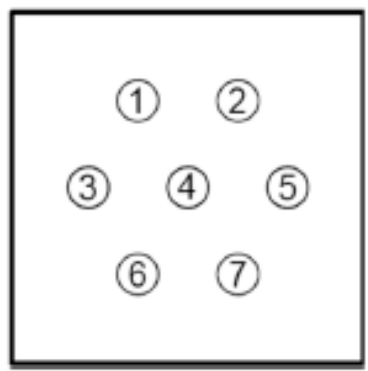

9 Piles

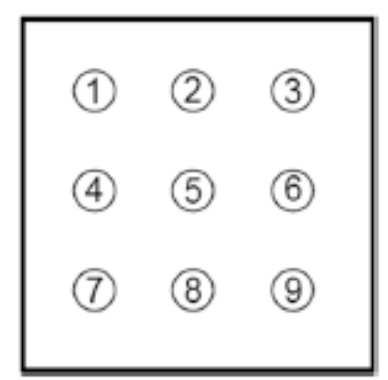

Figure 2. Pile group configurations considered in the finite element parametric study.

The study showed that accurate determination of the maximum number of defective piles a pile group can have without collapsing under applied loads, $\mathrm{m}$, is a key input parameter in binomial system-based reliability.

Wang and Kulhawy [12] developed a design approach that considers the construction economics of a foundation. In the optimization process, the objective is to minimize construction cost, and taking into account the design parameters and requirements as variables and constraints, respectively. The cost estimates were based on those of a spread footing in which the authors considered: excavation, formwork, reinforcement, concrete and compacted backfill. Ultimate limit state (ULS) and service limit state (SLS) requirements in consideration to the spread footing were based on the required factor of safety (FS) against soil failure and the allowable settlement. The key component in the study was the construction cost estimate for which a procedure was developed. Based on comparisons with existing conventional design examples the approach showed that savings in construction costs could be as much as $30 \%$. A sensitivity study was performed regarding the key soil properties that most affect the design and construction costs (Figure 3). It was found that when applied to cohesionless soils two parameters are important: the elastic module E of 
the soil and its friction angle. They significantly affect the design of spread footings. The Excel file used for solving the problem, free for use, can be obtained from the authors.

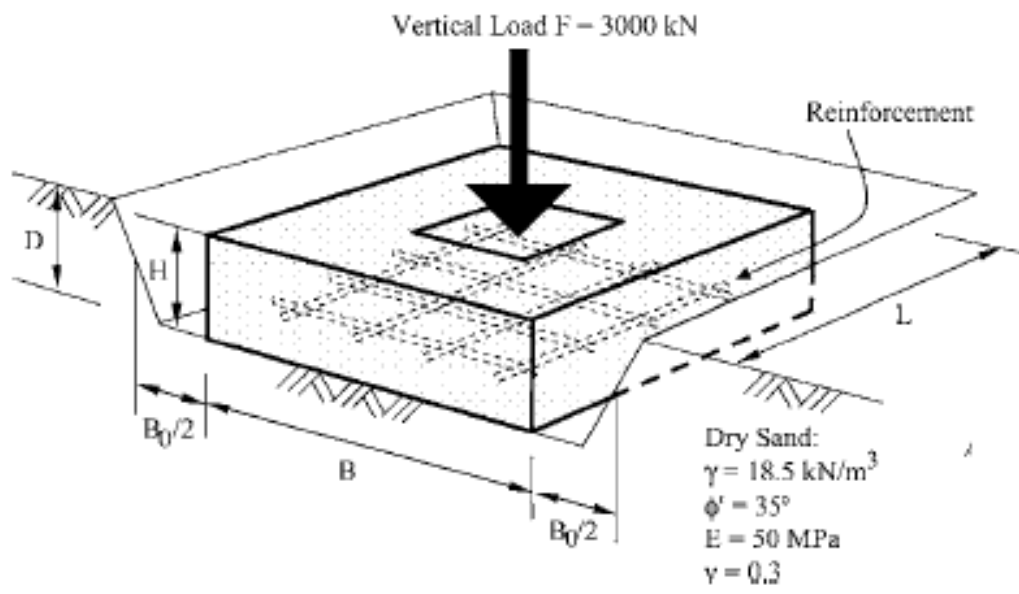

Figure 3. Spread footing design example.

Evolutionary algorithms such as differential algorithm (DE), evolution strategy (ES) and biogeography-based optimization algorithm (BBO) are increasingly used in geotechnical engineering. Kashani et al. [13] used these types of algorithm in foundation design optimization. The cost of shallow foundation designs that satisfy ACI 318-05 requirements is formulated as the objective function. The authors performed analysis based on routine optimization, and sensitivity analysis. The authors considered two different loading cases of the uniaxial and flexural moment applied to the shallow foundation. The location of the column on the footing was taken into account also. The other requirement was based on the elastic settlement of the footing. The paper explored extensively different cases of loading; uniaxial, axial and flexural at the center of the foundation and with dynamic location. The study was detailed and considered construction operations such as: excavation, concrete framework, reinforcement, concrete and compacted backfill. All the optimization algorithms were run 101 times, and the results reported in the form of best, worst, mean, SD, and median of successful runs. Results showed that only BBO and WDE (weighted differential algorithm) were able to deal successfully with all the cases.

Topology optimization combines finite element analysis with a numerical optimization algorithm in an iterative procedure. Seitz [14] proposed to use topology optimization for the foundation design of a strip footing. The principle of the approach consists in varying the material distribution inside the design domain in order to minimize the compliance; i.e., to minimize the deformations. Finite element analysis was used to evaluate in each iteration the structure's compliance. The numerical optimization algorithm follows by updating the material distribution based on the current design sensitivity. The author used Abaqus to apply the approach in three case studies: a pile foundation, a retaining wall and a vertically loaded plate. It was shown that the optimal topology is dependent on the structural system. Topology optimization leads to proposing alternative structures (topologies) with the same volume of material as the initial. The settlements were reduced up to $29 \%$ with the alternative topology of the vertically loaded plate for example. The method offers interesting paths for research and application in geotechnical engineering.

Shafiqul Islam and Rokonuzzaman [15] applied GA in optimization of foundations design. The variables of interest were the footing dimensions with depth and the total construction cost was considered as the objective function. The design requirements were considered as constraints in the approach. The coded algorithm was applied and permitted to show evolution of cost and settlements in terms of elastic modulus and friction angle of the soil. Comparison of the economically optimized design example with conventional designs showed that the savings in construction cost could be as much as $68 \%$. 
Jelusic and Zlender [16] presented an optimal design of pad footing based on multiparametric mixed-integer non-linear programming (MINLP) optimization. The authors developed a model in which the objective function targeted the structure production costs, subjected to design, resistance, rotation and settlement constraints within the ULS requirements of the Eurocode. The cost objective function comprises the production costs of a pad footing. Interest in the work resides in the fact that the optimization can be performed for different economic conditions and different design parameters. The approach was applied in real cases and has shown accurate results.

Pile-bearing capacity was approached by Murlidhar et al. [17] by using PSO, GA and ANN algorithms. The pile dynamics analyzer (PDA) test is considered as one of the most popular techniques to predict the ultimate pile capacity. The test was considered for validation of the techniques used to estimate the bearing capacity. The authors proposed the use of hybrid methods GA-ANN and PSO-ANN to draw practical conclusions. The authors selected PSO-ANN as the best predictive model of the ultimate capacity of driven piles. They also recommended its use as an initial predictive model for estimating ultimate capacity of piles before conducting tests.

Piled-raft foundation was used to support tall wind turbine in clay and sand. In such conditions an optimization procedure was proposed by Ravichandran et al. [18] based on estimation of the differential settlement. The wind speed and soil shear strength were taken as random variables that affect the design parameters (number and length of piles and radius of raft). Uniform probability distributions were considered for the undrained shear strength and the friction angle. The same type of distribution was used for the wind speed also. The authors used a bi-objective robust optimization tool namely NSGA-II available in MATLAB. It minimizes the effect of uncertainties on the response and capture well the optimal design in terms of cost efficiency and robustness. Comparisons were made between conventional design and optimized design, they have shown interesting results with easy-to-use graphs provided by the optimization procedure.

Pile lateral deflection was studied in terms of optimization methods by Zhang et al. [19]. The authors used a combination of the Elman neural network (ENN) and improved arithmetic optimizer (IAO) for predicting small-scale piles' lateral deflection. Number of physical models (192 in total) were provided by considering the most important factors on the lateral deflection under different situations. The proposed model proved to have proper performance and productivity in terms of predicting the piles' lateral deflection.

Kinzler and Grabe [20] presented a mono-criterial and multicriteria optimization problems of cost and settlement applied, respectively, to a quay wall structure and a pile foundation. Their optimization results concerning overall costs and displacements depended on different parameters such as pile border spacing, pile length, pile radius as well as beam width and beam height. The constrained multi-objective optimization problem was defined as:

$$
\operatorname{Min}\{f(x)|x v M| g(x)=0 ; h(x) \leq 0\}
$$

where $f(x)$ is an objective function with constraints $g(x)$ and inequalities $h(x)$. The Pareto optimal set was also used in the examined combinations of parameters. The paper presented a general view on optimization in geotechnics, with a discussion of the difficulties related to non-linearity, multi-modality, and discontinuity.

Problems of scour at pile groups have various aspects, and can be approached in terms of optimization especially in coastal and rivers contexts. Azimi et al. [21] proposed an original approach based on evolutionary Pareto optimization combined with an ANFIS (adaptive neural fuzzy inference system) network for modelling scour at pile group in the context of clear water. The authors first determined the most effective parameters on predicting scour at pile groups, which consist of critical velocity of the sediment, mean particle diameter, flow depth, pile diameter, centre-to-centre distance between adjacent piles in line with the flow, centre-to-centre distance between adjacent piles perpendicular to the flow, number of piles parallel to the flow and number of piles normal to the flow. 
Sensitivity analysis was carried out to identify the effect of each parameter on predicting scour at pile groups. The authors provided pseudo-codes in which the programming steps can be followed and reproduced. The article is, technically, well furnished and detailed, and it permitted determination of the most influential parameters on scour depth as the pile diameter and the number of piles perpendicular to the flow direction.

Cost-effectiveness, construction time, load capacity and/or serviceability were of interest in the study of Kinzler and Grabe [22] in which they proposed systematic approaches for optimizing geotechnical constructions. The authors worked on mono-objective and multi-objective optimization problems. The approach was based on using EA (evolutionary algorithms) which are population-based iteration schemes, to examine in each iteration step parallel multiple parameters sets. Two worked examples showed good applicability of the proposed method: mono-objective optimization of a quay wall structure and a multi-objective optimization of a combined pile-raft foundation.

Metaheuristic optimization algorithms have gained wide utilisation in geotechnics in the last 10 years. In their work on the design of a pile wall retaining system during deep excavation, Taiyari et al. [23] implemented four different optimization techniques including GA, PSO, bee algorithm (BA), and BBO. The total cost of the retaining structures is considered as an objective function, which should be minimized in the design space of the variables. The worked example was taken from Tabriz Metro, and contains different aspects of a geotechnical project. Based on the results obtained from the analysis it was shown that normalized objective values obtained by the GA, PSO, and BBO algorithms relative to the BA were, respectively, $22 \%, 8 \%$, and $17 \%$ higher. In terms of convergence rates of the considered algorithms BA showed very good results with respect to the other algorithms. Sensitivity analysis was not carried out in this study.

Chow and Thevendran [24] were interested in the optimization of pile groups with rigid caps or rafts where the objective is to determine the distribution of lengths of a given layout of the group piles. The idea is to keep the total load evenly distributed over the piles while the stiffness of the group remains within certain limit percentage of the stiffness of the original pile group of uniform length. They used a simple optimization technique in conjunction with a method for pile group settlement analysis. The approach worked well and showed good results. They found that in large pile groups, where accurate estimation of the stiffness of the raft is difficult, the optimized pile group is likely to perform more satisfactorily. The work of Chow and Thevendran can be considered as a precursor in the field.

Lestios et al. [25] worked on the optimization of methodologies for pile foundations. They focused on best pile foundation design in terms of performance and economy in accordance with two design code recommendations, namely Eurocode 7 and DIN 4014 The soil-pile interaction was considered by the use of finite elements. The optimization problem, based on EA, was presented in terms of minimizing the total cost of piles subject to constraints. The variables considered in the optimization were the pile length, the pile diameter and the number of piles. Two real-world buildings were considered in the study and the results obtained indicated that depending on the soil conditions DIN design procedure can become more conservative compared to the EC7 and vice versa. The benefit in terms of construction cost of the optimum designs varies from $7 \%$ to $33 \%$ compared to original solutions. The authors did not mention in detail how EA can be programmed.

The monopiles used for offshore wind turbines are subject to a multitude of parameters and their design constitutes a challenge in terms of optimization when it is generalized to an entire wind farm (50 to 150 structures). Kallehave et al. [26] presented an interesting review on the subject. Many design parameters are of interest for a turbine among which are pilesoil stiffness, height of scour protection, wall thickness, marine growth, external loadings etc. The authors detailed the role of each parameter and described different approaches used to consider them. It was shown that there is a potential for further optimization of monopole support structures compared to the current state of practice. Reducing costs 
in relation to the steel quantities depends on site conditions, and thus improved design methods are needed for better optimization.

In the context of using piles as retaining systems to stabilize a multi-layered slope, Zhang et al. [27] conducted a study for optimizing the appropriate configuration that will ensure stability. They solved the problem by using an analytical method to design the plane arrangement of stabilising piles under spatial lateral load of multi-layered sliding masses. The interest of the study lies in the combination of slope stability with the piles group as a whole system. The distributed landslide lateral load is essential to determine the position of stabilizing piles and pile spacing. The authors provided a very detailed study on how the lateral load was obtained based on the 3D sliding mass. The unified strength theory was employed to determine the condition of soil strength. The method of determining the arrangement of stabilising piles was developed by considering the cost and performance of piles based on failure probability via Monte-Carlo method. The authors found very interesting results when the method was applied in a real case study (Bazimen landslide).

In the same context of using micro-piles for landslide safety protection, Liang et al. [28] proposed to work with machine learning tools for the design of pile arrangement, spacing, row spacing, anchoring depth, sizes and reinforcement bars of piles. The methodology is based on the combination of micro-pile arrangement with the landslide thrust. The results are given in terms of internal forces of micro-piles for an optimal configuration.

Offshore geotechnics have gained momentum during the last few years, and with this optimization became prominent in number of applications. Cerfontaine et al. [29] studied optimization of screw anchors in offshore geotechnics. As they pointed to the optimization of screw anchor design relies on more than the geotechnical assessment of the uplift capacity based on soil strength, the installation requirements and structural constraints are of high importance. In the optimization process the authors considered the maximum depth $\mathrm{L}$ (and then capacity $\mathrm{H}$ ) that can be reached for a given screw anchor geometry $(\mathrm{Dc}, \mathrm{Dh} / \mathrm{Dc}=2, \mathrm{tc})$ in a given soil. Different scenarios were assumed regarding the maximum torque available during installation (Tmax, varying between $1 \mathrm{MNm}$ and $15 \mathrm{MNm}$ ). The results obtained are of practical interest and open new doors on the design of screw anchors which depends on both structural (core strength, helix strength) and geotechnical (capacity, installation requirements) constraints, which must all be assessed prior to installation and operation. A design chart is provided to quickly assess the optimal capacity in a dense layer of sand.

\section{Optimization Methods for Slope Stability Analysis}

Geotechnical problems are complex because of multivariable dependencies of soil responses and uncertain behaviour of soils. Optimization in geotechnics is presented to fulfil two main points: (1) meeting the minimum requirements to reach the demanding serviceability of a geotechnical structure and (2) finding the best choice among lots of possibilities. There are many cases in which the objective function is non-convex and discontinuous with lots of strong local minima within their solution domain. Metaheuristic optimization algorithms such as GA, PSO, SAO (surface altering optimization), DE (differential evolution) and others have shown strong practice when applied to slope stability and retaining structures problems. With the help of Rocscience's Slide2 software, Kashani and Ghadomi [30] used metaheurstic algorithms for optimization of geotechnical problems and showed interesting aspects of applying different algorithms. Comparisons were given and varieties of results were obtained depending on the algorithm in practice. In the slope stability analysis, the evaluated factor of safety varies due to the high complexity of the problem (between 1.659 and 1.055). This considerable variation proves that any error in this regard can result in a catastrophic disaster. The numerical examples also demonstrate the significant impact that metaheuristic algorithms have on the handling of this problem. For the retaining structure analysis, the final cost and weight results varied from one algorithm to another, with variations of $12.25 \%$ and $7.6 \%$ for final cost and weight, respectively. 
Considering the huge volume of these structures, selecting an appropriate algorithm for handling the problem can result in huge savings in construction costs.

Chen and Shao earlier in 1988 [31] employed simplex, steepest descent, and DavidonFletcher-Powell (DFP) methods for evaluation of minimum factor of safety in slope stability analysis. In their analysis, the authors included in the routine procedure comparing a number of admissible surfaces that are selected by random searches. They showed that the selected methods can provide reasonable results and they found also that modifications to the DFP method were essential for successful implementation of the minimization procedure.

A combination of rigid finite elements and non-linear programming was used by Chen et al. [32] for slope stability analysis in terms of upper bound limit. The proposed formulation is new and applies to two and three dimensional slope stability problems. An objective function consists in finding the minimum value of the factor of safety using an optimization method. Non-linear programming was adopted for this purpose and validated in test examples. According to the authors, the method is simpler than similar approaches that employ linear finite elements.

Basson and Ramana [33] made a comparison of slope stability using SPH (smoothed particle hydrodynamics), FEM (finite element method) and LEM (limit equilibrium method). The theory and framework of different methods were presented, and the analysis was carried out for different geometries and material parameters. The main conclusion in the study is that the limit equilibrium method and finite element method can predict the probable failure surface and the corresponding factor of safety, but they cannot predict the pre-failure and post-failure profiles. SPH helps overcome the problem, and it is implemented to simulate the run out of an MSW flow failure. The predicted runout and failure geometry using $\mathrm{SPH}$ is close to the survey reported as post-failure analysis presented in the literature.

A gravitational search algorithm (GSA) with the sequential quadratic programming (SQP), namely GSASQP, were used as hybrid algorithm for optimization of the factor of safety in slope stability analysis [34]. GSA is based on the gravitational law and laws of motion. The method simulates mass interactions, and movement through a multidimensional search space under the influence of gravitation. SQP is used for searching locally accurate local exploitation. The combination of the two methods resulted in a well-described program for slope stability analysis. The approach was applied in three different cases (homogenous soil, multi-layered soil, and a slope with a weak layer subjected to water pressure). The results obtained show a good practice for the proposed method, but computing time was not mentioned. The algorithms were simulated 30 times independently, the statistical analyses were carried out and for each method.

An example of Geogrid-reinforced retaining structure that was studied by Rowshanzamir and Aghayarzadeh [35] is related to retaining walls with various oblique angles of reinforcement layers as well as a tilted face to achieve optimal design alternatives. A finite difference-based approach was used by the means of software FLAC 3D. Wall face deformations were traced as well as the distribution of reinforcement force, backfill settlement and sliding surface. The numerical modelling was first verified against existing cases and a parametric study was performed for an optimized design.

Jellali and Frikha [36] discussed the resolution methods of non-linear constrained optimization problems that can be divided into deterministic and stochastic. The deterministic methods use generally significant hypotheses about objective functions, such as the continuity and differentiability. To overcome the difficulties of deterministic methods, other types of algorithm for constrained optimization were developed. The EA algorithm is one of them and it applies the principles of evolution found in nature to derive an optimal global solution. The authors applied a constrained PSO algorithm to slope stability. The use of PSO necessitated the transformation of the problem into an unconstrained equivalent one to determine the critical factor of stability.

PSO has been extensively used in geotechnical engineering. The approach is evolutionary in terms of computation as it is based on simulation of a simplified social system. 
The system is initialized with a population of random solutions that are updated during iterations. Hajihassani et al. [37] made an interesting review on the use of PSO in geotechnics in general with special applications in slope stability problems, pile and foundations, tunnelling as well as in underground space design. A description of the method is given in a first stage followed by applications in different fields of geotechnical engineering. It was shown that PSO plays a significant role as an optimization algorithm to predict/optimize geotechnical outputs but it should be utilized with caution in addition to sensitivity analysis on initial parameters to avoid returning disappointing results.

Optimization of slope-stabilisation systems was studied by Wang et al. [38] by applying a combined approach of a gabion-faced geogrid-reinforced retaining wall with embedded piles. The integrated system is challenging as the engineering cost is relatively high, and this phenomenon can be attributed to the material redundancy. The authors compared indicators of slope stability in various slope configurations based on the site conditions. Four typical slope examples were analysed to ensure the validity of the strength reduction finite element method (SR-FEM) conducted in Abaqus. Based on the optimization process of the integrated slope-stabilisation system it was found that $36 \%$ of the area of the geogrid used on the site and $35 \%$ of the volume of piling can be reduced. The applied method has shown effectiveness, especially in reducing the cost of the project. The results of the optimized value of the major design parameters can be used as the threshold value when other slope sites stabilised by the same integrated system are used.

Optimization of parameters of soil nailing was the subject of research conducted by Benayoun et al. [39]. Response surface methodology (RSM) was used in combination with a finite element method for optimizing geometric parameters of a soil nailing system. The cost was also considered in the multi-objective optimization approach. The authors analysed the results by ANOVA to reveal the most effective parameters in the process. Contour lines were used to show the influence of the most influential parameters.

Eun-Chul et al. [40] formulated a constrained optimization problem in the context of slope stability analysis based on the use of GA. The study gives detailed steps for the analysis and showed results of a case study using Spencer's method. The method is convenient to solve nonlinear equilibrium equations and finding the factor of safety and the critical slip surface.

Liao and Liao [41] used backpropagation neural networks (BPNN) and multivariate adaptive regression splines (MARS) to capture the intrinsic nonlinear and multidimensional relationship among the parameters associated with the evaluation of slope stability. The authors based the analysis on data collected from several history cases (153 in total). Six influencing factors were considered to present the character of the slope. They included unit weight $(\gamma)$, cohesion (c), internal friction angle $(\alpha)$, slope angle $(\beta)$, slope height $(H)$, and pore pressure ratio $(\mathrm{Ru})$. The predicted safety factor and target value based on the use of BPNN were very close and accurately calculated. BPNN and MARS models can model the relationship between the safety factor and the slope parameters. The correlation coefficient R2 in the BPNN model is 0.8931, and the value in the MARS model is 0.8629 . Accurate results were obtained regarding the relative importance of the input variables based on both models, BPNN and MARS. It was shown also that the MARS model has the advantage of computational efficiency and easy interpretation.

A combination of QPSO (quantum-behaved particle swarm optimization) and the LSSVM (least squares support vector machine) algorithm was used by Li et al. [42] in slope stability analysis. The aim was to better take into account non-linear relationships between factor of safety (FS) and influencing factors. The authors used 25 training samples and six testing samples that were collected from existing data. The use of QPSO in combination with LSSVM helped avoiding complex failure mechanism and highly non-linear characteristic of slope stability. The method allows learning the relationship among physical and mechanical parameters and the factor of safety. QPSO-LSSVM has shown quick search velocity as well as good convergence performance. 
In order to consider spatial variability in slope stability analysis, Javankhoshdel et al. [43] proposed the use of non-circular random limit equilibrium method (RLEM) combined with an optimization technique. A Monte Carlo optimization (MCO) technique and SAO were applied and compared. The article is well documented with a detailed presentation of the methods and how they can be applied in the case of spatial variability of soil conditions. A tailings dam was studied with different layers of soil and considering spatial variability of soil properties; only vertical correlation was considered based on measures of CPT at different locations. The results showed that SAO has more capabilities in capturing the failure paths with faster computing time than the MCO approach. The SAO method gave upper bound values of probability of failure (i.e., it found more critical failure surfaces) compared to the case with $\mathrm{MCO}$ and the case with no optimization.

An interesting chapter by Pandit et al. [44] dealt with optimization techniques in slope stability analysis methods. The fundamentals of different optimization techniques were given and detailed. The authors considered linear programming (LP), non-linear programming (NLP), dynamic programming (DP), the interior point method (IPM) and heuristic algorithms such as GA, simulated annealing (SA), swarm intelligence (SI) and harmonic search optimization (HSO). The optimization process was presented in terms of Limit Equilibrium Method. The chapter was enriched also by a review on different techniques for deterministic slope stability analysis and stochastic slope stability analysis.

Many geotechnical problems are not governed by continuous convex optimization processes. A very interesting description of the use of hybrid metaheuristic algorithms in geotechnical engineering was given by Cheng [45]. The author described some complicated one-dimensional functions with several "strong" maxima and minima as they can be encountered in geotechnics (the PDA test, for example). The need for using heuristic optimization analysis is well explained and argued. Worked examples were added at the end of the chapter to show the abilities of hybrid heuristic optimization methods such as PSO, chaos harmony search algorithm ( $\mathrm{CH} / \mathrm{HS})$ and genetic algorithm/harmony search (GA/HS). The methods were applied in different types of problems (PDA, slope stability). According to the author's experience, it is difficult to design a set of parameters which are suitable for all types of condition. Every method has its own merits and limitations. For difficult problems where there are many local minima, the use of the hybrid methods are more effective at the expense of minor increase in the amount of computations.

The multiverse optimization algorithm (MVO) is among the nature-inspired approaches that was coined in 2016 by Mirjalili et al. [46]. The main inspirations of this algorithm are based on three concepts in cosmology: white hole, black hole, and wormhole. In 2020, Mishra et al. [47] used MOA for capturing the critical slip surface in slope stability analysis. It was applied for slip surface generation and factor of safety calculation. The proposed algorithm was tested on four case studies, one with homogeneous slope and three others with heterogeneous slopes of different complexities. The critical factor of safety was calculated with high accuracy and MVO can also capture the weak soil layer sandwiched between two strong layers. The results obtained were compared with different techniques such as GA and PSO among others. The main advantage stands in the few adjustable variables used by MVO, which makes it simpler to use in comparison to other metaheuristic approaches (GA, PSO ... ).

Azizi [48] combined three recent optimization methods, hybrid artificial bee colony algorithm with differential evolution (HABCDE), grasshopper optimization algorithm (GOA) and improved harmony search algorithm (LHS), with a non-circular surface generation scheme to identify location of the slip surface. The objective function (factor of safety) was optimized (minimized) based on a concise form of the Morgenstern-Price algorithm. The slip surface was considered to be non-circular. The comparative study between the three methods was conducted in detail with good illustrations of the convergence rates. Different case studies were considered.

To estimate the critical factor of safety FS of a homogenous finite slope, Erzin and Cetin [49] applied neural networks (ANN) and multiple regressions (MR). After a compre- 
hensive presentation of the two methods the authors have shown the utility and how to apply them for calculating the optimal factor of safety. The results demonstrated that the ANN models can be used at the preliminary stage of designing homogeneous finite slopes, they exhibit more reliable predictions than the MR models.

A three-dimensional slope analysis was conducted by Kalatehjari et al. [50] for finding the optimal safety factor based on the PSO algorithm. PSO is widely used in different domains, and in geotechnics it gained a lot of use as shown in the examples run by Kalatehjari et al., (2014) by using Plaxis 3D in their simulations.

Random limit equilibrium method combined with SAO was used to analyse noncircular failure in slopes. The method proposed by Mafi et al. [51] is interesting as it enables searching for the failure surface randomly in combination with an optimization process. Combination of SAO and random limit equilibrium offers fast convergence while reducing the risk of local minimum entrapment. The method was validated and applied on a tailing dam with different layers of soil and considering spatial variability of soil properties). The probabilistic analysis was computationally intensive, and it can be time-consuming.

Many optimization algorithms have been used in slope stability analysis. Reale et al. [52] pointed to a multi-modal analysis for analysing the reliability of slope stability. The authors based their study on probabilistic analysis as a tool for finding optimal failure surfaces. They proposed the use of a locally informed particle swarm optimization method (LIPS), which is able to simultaneously converge to multiple critical slip surfaces, in combination with a reliability analysis able to define all areas of concern within a slope. FORM (first order reliability method) was used. The case study was a rail embankment consisting of a shallow weak silty clay layer overlying a stiffer clay deposit. The presented model is limited to circular slip surfaces. The article is interesting as it shows how to proceed with the combination of LIPS and FORM to analyse the stability of the slope.

Mphatiwa and Cawood [53] submitted a study on the design of an optimal system for slope monitoring. The steepening of slope angles has implications for the safety and economics of the mining operation. The steeper the slope angles, the greater the probability of slope failure. The authors provided guidelines on how to design an optimal survey slope monitoring system. In their view, a survey monitoring system should adhere to survey principles such as working from the whole to part and consistently cross-checking. Geo-referenced systems were used, they include, among others, the Geodetic Monitoring System (GeoMos), Slope Monitoring Radar (SSR), and the Global Positioning System (GPS) technology. In the authors' opinion, no matter how sophisticated the instrumentation or the software is, if the foundation or design is not optimal, the level of confidence in the monitoring results will be low. They applied the approach at Jwaneng Mine where extension of open pit was planned. A strategy for optimizing the process of slope monitoring was proposed and followed by practice in the field. It is evident that although slope monitoring has evolved towards more automated processes, basic survey principles such as working from whole to part, cross-checking, documentation of procedures, and error adjustment are still required for reliable results to be achieved.

Within slope stability analysis an optimization of strength reduction was proposed by Dyson and Tolooiyan [54]. The study aimed at incorporating a modified strength reduction definition, allowing for a refinement of the factor of safety search space. Comparisons were made with the traditional technique. The authors implemented in-house Python and FORTRAN codes in conjunction with Abaqus for the strength reduction of FEM slope stability simulations. For slopes with small friction angles (e.g., soft clays) the authors introduced a reduction method where the initial $\phi$ gradient is steeper than the cohesion c, which reduces the number of strength reduction steps to achieve a factor of safety. The accuracy and computational efficiency were studied through five forms of analysis. One of the main concerns with the proposed strength reduction method is the judgement process for considering when the final slope deformation failure state is attained. The authors proposed an approach based on defining specific criteria. The calculation of the factor of safety based on 3D analysis was found to be time consuming in comparison to the results 
obtained using 2D analysis. The proposed technique can be an effective tool for geometries consisting of a large number of finite elements.

\section{Optimization Methods for Soil Parameters and Investigations}

The constitutive models in use for soils are based on a number of parameters that need calibration. Ter-Martirosyan et al. [55] described a methodology for optimizing the parameters for soil models included in a finite element software (PLAXIS 3D). The focus was on two particular models, the Hardening Soil model and the Soft Soil Creep model. A comparative analysis of the results of laboratory soil tests with the models was carried out. For a reliable description of the actual behavior of the soil, the authors found it necessary to calibrate the parameters of the model, based of the significance of the parameters in simulating a laboratory test. A reliable determination of parameters depends mainly on the initial stress state.

A type of optimization strategy was used by Gaone et al. [56] for evaluating soil parameters of a modified cam clay (MCC) model for self-boring pressuremeter data. Challenges were reported when deriving MCC parameters from undrained triaxial compression tests. The general approach adopted by the authors is based on a two-step single variable optimization approach for normally consolidated triaxial data. The authors pointed to the importance of deriving the initial mean effective stress. Undrained shear strength from final slope of pressuremeter curve is of importance also. The difference in the proposed optimization technique lies in the concept of two-step single variable which was applied to pressuremeter data. The interest of the study resides in the combination of field results (pressuremeter) and the approach proposed by the authors is based on a clear methodology for optimizing the soil parameter when MCC is applied. The optimization process is divided into number of steps as shown in Figure 4.

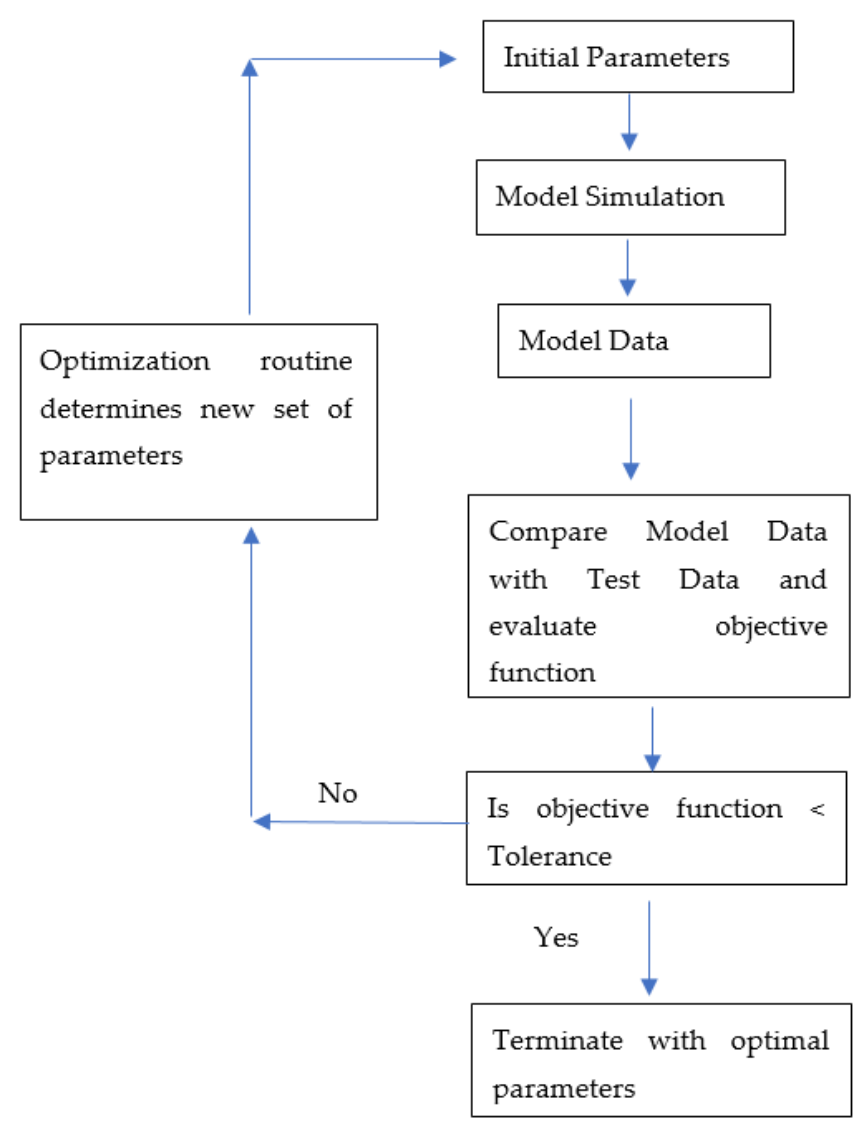

Figure 4. Flow chart of the optimization process. 
The objective function was formed by summing the minimum distances of each of the $\mathrm{n}$ test data from a straight-line fit between the two nearest model data points (Figure 5).

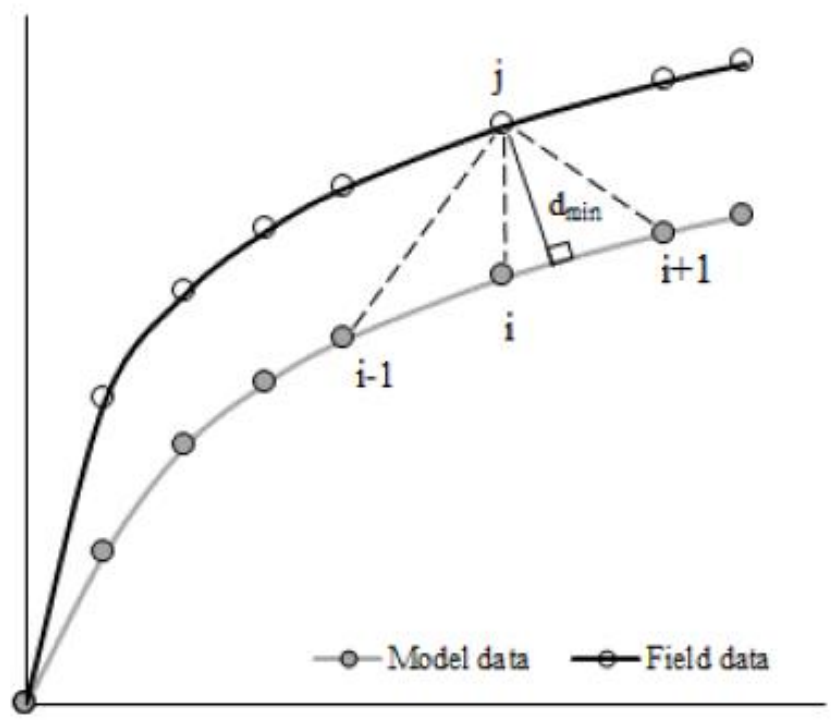

Figure 5. Derivation of a scalar value.

The automated strategy was applied and validated on real case studies; it showed very interesting results.

For identifying soil parameters Yin et al. [57] used different optimization techniques. The procedure of optimization consisted in two steps: (1) formulation of an error function measuring the difference between model responses and experimental results; and (2) selection of an optimization strategy to enable the search for the minimum of this error function. The authors applied five optimization methods: GA, PSO, simulated annealing (SA), the differential evolution algorithm (DE) and the artificial bee colony algorithm (ABC). The data were based on synthetic pressuremeter results. The study was interesting as it shows the differences in the results obtained by the aforementioned methods from which DE has shown particular abilities for searching the optimum but with slow convergence speed. The methods used could reach approximate solutions with very small objective errors, but these solutions were different from the preset parameters. To remedy the problem the authors proposed a new approach based on the Nelder-Mead simplex method, which indeed helped improving the identification performance.

Selecting the appropriate parameters when calibrating a soil constitutive model is not an easy task. Among the issues that affect a proper calibration are the site stratigraphy and the number of parameters in the soil constitutive model. Calvello and Finno [58] used an inverse analysis approach for selecting the parameters to optimize. The problem was in identifying the important parameters to include in the inverse analysis. Figure 6 shows a schematic view of inverse analysis procedure.

The authors worked on an elastic-plastic, multi-yield surface Hardening-Soil model. Failure is defined by the Mohr-Coulomb failure criterion. Among the parameters of the model are: friction angles, cohesion, dilatancy angle. The H-S model input parameters can be derived from the results of drained triaxial compression and standard consolidation tests. The parameter optimization algorithm based on inverse analysis was applied to efficiently calibrate the soil model by minimizing the errors between experimental observations and computed responses. The computed results fit the experimental data. 


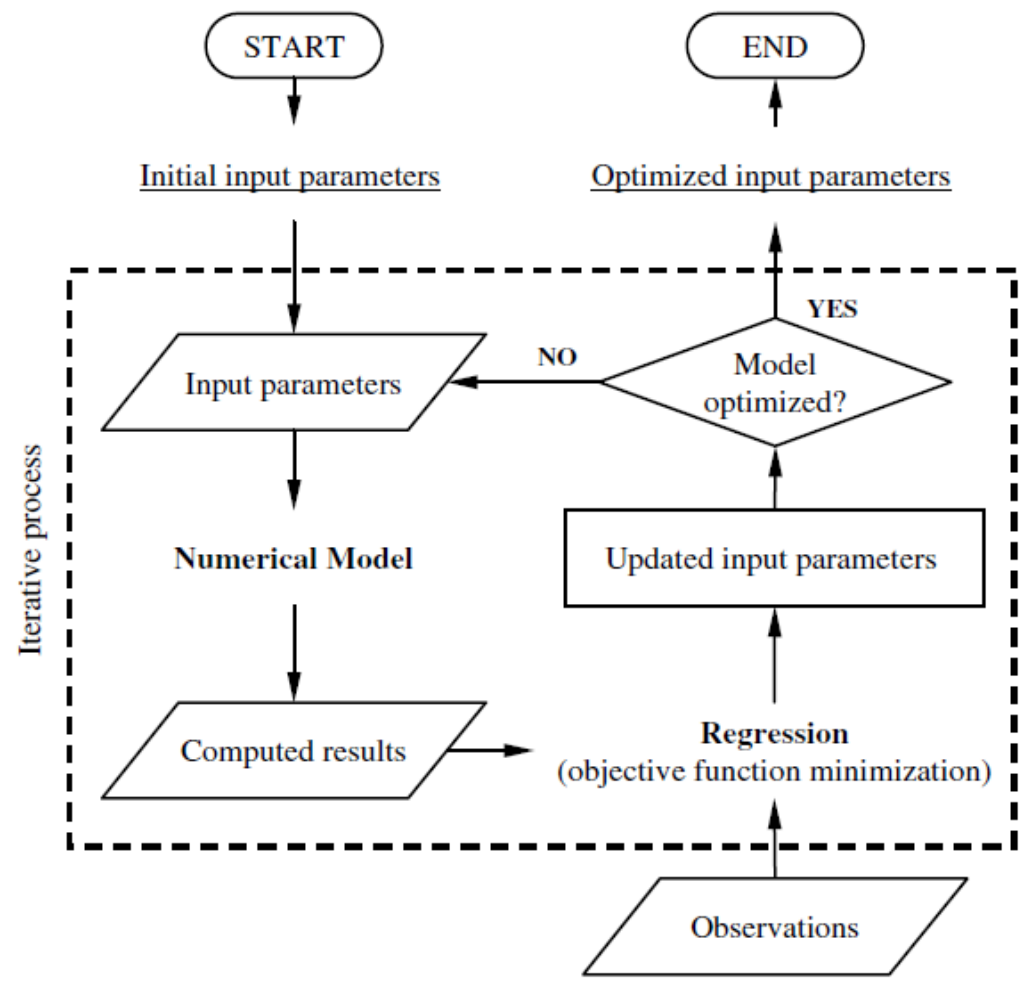

Figure 6. Schematic of inverse analysis procedure.

Geotechnical engineers in general use ranges of values for soil properties as they cannot be determined with exactitude. Varga et al. [59] worked on this aspect while studying the optimal design of gravity retaining walls. A wide range of input parameters were used to determine an optimal design. The authors developed a multiparametric approach that considers design parameters for a minimal construction cost of gravity walls. GA was used to optimize the objective function given a number of constraints. Sensitivity analysis was carried out to find the most influential parameters on the design. The parametric analysis of a gravity wall permitted finding the optimal design for 567 combinations, and it helped to develop useful diagrams illustrated with examples.

In a recent study, Mahmoudi et al. [60] combined BIM with geostatistics for optimizing geotechnical surveys. An interesting approach was proposed to construct a spatial ground model for subsequent experimental or numerical analysis. For a given geotechnical survey, the authors applied the combined approach to generate locations for new boreholes, and quantify their uncertainties. The impact of the new borehole on the uncertainty measures are quantified based on local and global approaches. The proposed concept can identify the geological models' risky locations for further geological investigations and reveal an optimized experimental design.

Boumezerane et al. [61,62] proposed a method for optimizing soundings density for geotechnical investigations. The approach is based on fuzzy reasoning, by considering different parameters that can influence geotechnical investigations. Soil variability and geology as well as the type of project are of primary importance and expressed as fuzzy sets based on the engineer's judgement. The approach was applied on real case studies and showed encouraging results.

A similar type of optimization related to estimation of number of soundings was investigated by Zlender et al. [63] while using ANFIS. The advantage of the approach lies in the capabilities of ANFIS which helps in defining the input fuzzy sets. The method was applied at locations where it demonstrated good efficiency.

For optimizing a soundings location in a spatially variable soil, Chwala [64] proposed a novel, interesting approach that allows evaluating the bearing capacity of rectangular shal- 
low foundations with consideration of soil spatial variability and soil sounding locations. The method combines Vanmarcke's spatial averaging and kinematic failure mechanisms. To illustrate the abilities of the proposed approach the author applied it in an example of rectangular foundation and two boreholes. The approach can be used for complex foundation arrangements and a greater number of soil soundings.

Adaptive metamodels help finding optimal solutions based on iterative processes. In a profound study on reliability-based optimization of geotechnical systems, Wang and Owens [65] presented a methodology of minimizing an objective function such as material quantity or cost subject to design requirements specified by probabilistic constraints using a decoupled approach of adaptive metamodels. The concept of adaptive metamodels of a reliability index function is illustrated in Figure 7. A one-dimensional problem with only one design variable $D_{v}$ is illustrated. With the initial sample points, an initial metamodel, $\beta\left(D_{v}\right)$ of the original reliability index is created. The iterative process consists in carrying out optimization to find an optimal point in the design space $D_{v}^{*}$. The first order reliability method (FORM) for the design of geotechnical structures was used in combination with the metamodels. The obtained results from different examples (e.g., shallow foundations, piles, gravity retaining wall) have shown clearly the advantage of decoupling reliability analysis and numerical optimization when performed in a sequence. The methodology improved the accuracy of the reliability analysis in optimization.

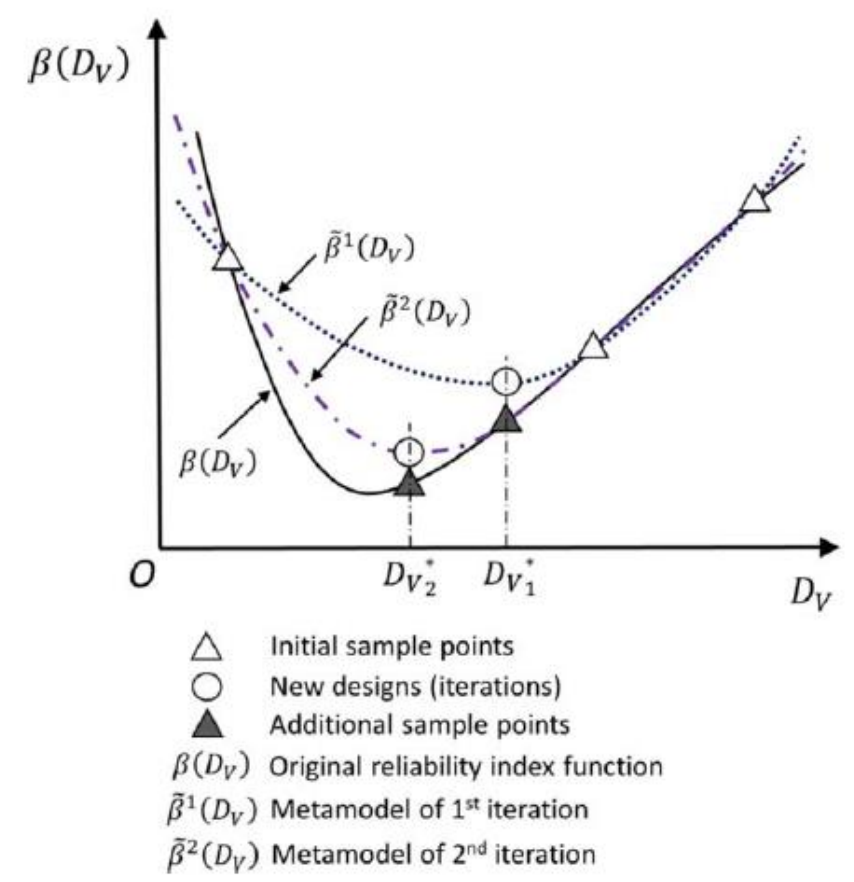

Figure 7. Adaptive metamodels of a reliability index function.

The proposed method can remedy the issues of deterministic design optimization approaches in which the results cannot meet the required reliability index levels. With this strategy, the designs can meet the reliability requirements under multiple failure modes.

Searching for maximum discontinuity frequency in rock engineering has been the subject of a research carried out by Simpson and Priest [66]. The authors applied GA for the purpose. The article is well documented and the use of GA was well argued and explained. It was successfully applied for optimizing the intersecting rock fracture planes.

\section{Discussion}

Most of the techniques used recently for optimization in geotechnics rely on metaheuristic methods such as GA, PSO, ANN etc. The non-linearities of objective functions in a geotechnical context makes it difficult to use simple deterministic methods. As we can 
see in Table 1, GA and PSO were extensively used in comparison to the other methods. Optimization methods were broadly used in slope stability analysis more than in foundations or soil investigations.

Table 1. Occurrence of different optimization methods.

\begin{tabular}{|c|c|c|c|c|}
\hline Methods & Foundations & $\begin{array}{l}\text { Slope } \\
\text { Stability }\end{array}$ & $\begin{array}{l}\text { Soil Properties and } \\
\text { Investigation }\end{array}$ & Total \\
\hline GA Genetic Algorithm & 5 & 4 & 3 & 12 \\
\hline PSO Particle Swarm Opt. & 3 & 7 & 1 & 11 \\
\hline ANN Artificial Neural Networks & 3 & 2 & & 5 \\
\hline SAO Surface Altering Optimization & & 4 & & 4 \\
\hline DE Differential Evolution & 1 & 2 & 1 & 4 \\
\hline ABC Artificial Bee Colony & 2 & 1 & 1 & 4 \\
\hline NLP Non Linear Programming & 1 & 3 & & 4 \\
\hline ANFIS and Fuzzy sets & 1 & & 3 & 4 \\
\hline DLO Discrete Layout Optimization & 4 & & & 4 \\
\hline EA Evolutionary Algorithm & 3 & & & 3 \\
\hline HS Harmony Search & & 3 & & 3 \\
\hline Reliability methods & 1 & 1 & 1 & 3 \\
\hline BBO Bio-geo Based Algorithm & 2 & & & 2 \\
\hline MCO Monte Carlo Optimization & 1 & 1 & & 2 \\
\hline AC Ant Colony & 1 & & & 1 \\
\hline MR Multiple Regressions & & 1 & & 1 \\
\hline GOA Grasshopper Opt. Algorithm & & 1 & & 1 \\
\hline MVO Multiverse Opt. Algorithm & & 1 & & 1 \\
\hline $\begin{array}{c}\text { GSA Gravitational Search } \\
\text { Algorithm }\end{array}$ & & 1 & & 1 \\
\hline SPH Smooth Part. Hydrodynamics & & 1 & & 1 \\
\hline IAO Improved Arith. Optimizer & 1 & & & 1 \\
\hline IPM Interior Point Method & & 1 & & 1 \\
\hline $\begin{array}{l}\text { MARS M.variate Adap. Regr. } \\
\text { Splines }\end{array}$ & & 1 & & 1 \\
\hline Topology Optimization & 1 & & & 1 \\
\hline RSM Res. Surface Methodology & & 1 & & 1 \\
\hline Least Squares Method & & 1 & & 1 \\
\hline Geostatistics & & & 1 & 1 \\
\hline Adaptive Metamodels & & & 1 & 1 \\
\hline Inverse Analysis & & & 1 & 1 \\
\hline \multirow[t]{2}{*}{ Others } & 8 & 4 & 3 & 15 \\
\hline & 39 & 41 & 16 & 95 \\
\hline
\end{tabular}

\section{Conclusions}

We performed a non-exhaustive review of the new tendencies in the use of optimization methods in geotechnics during the last few years. Three main domains of geotechnics were considered: foundations, slope stability, soil properties and investigations. It was shown that most of the techniques used rely on metaheuristic methods which appeared to deal efficiently with the non-linearities encountered in many geotechnical problems. Deterministic methods are increasingly less able to solve the complex situations that arise, notably, in ground conditions. The particularity of geotechnical problems is that in each case a special approach needs to be adopted. Knowing the parameters that can describe soil variability is significant, as it can give guidance on which type of optimization to perform. Particle swarm optimization as well as genetic algorithms and other metaheuristic methods present a number of advantages that lead them to be used in many complex situations. Computational time should, on the other hand, be considered as an important parameter. Some of the optimization methods draw attention as they contain new approaches that can be developed to broader applicability, among them we can cite DLO (discrete layout optimization) [2], topology optimization [14] and a technique combining Vanmarcke's spatial averaging with kinematic failure mechanisms [64]. Further studies can help when interpreting, in particular situations, the usefulness of each optimization method.

Funding: This research received no external funding. 
Conflicts of Interest: The author declares no conflict of interest.

\section{References}

1. Konietzky, H.; Herbst, M. Optimization in Geotechnics; TU Bergakademie Freiberg, Institut für Geotechnik: Freiberg, Germany, 2017.

2. Smith, C.C.; Gilbert, M.; He, L.; González-Castejón, J.; Ouakka, S. Recent advances in the application of discontinuity layout optimization to geotechnical analysis and design problems. In Proceedings of the XVII ECSMGE-2019 Geotechnical Engineering Foundation of the Future, Reykjavik, Iceland, 1-6 September 2019; ISBN 978-9935-9436-1-3. [CrossRef]

3. Smith, C.; Gilbert, M. Application of discontinuity layout optimization to plane plasticity problems. Proc. R. Soc. A 2007, 463, 2461-2484. [CrossRef]

4. Gilbert, M.; Smith, C.C.; Haslam, I.W.; Pritchard, T.J. Application of Discontinuity Layout Optimization to geotechnical limit analysis problems. In Numerical Methods in Geotechnical Engineering; Benz, T., Nordal, S., Eds.; Taylor \& Francis Group: London, UK, 2010; ISBN 978-0-415-59239-0.

5. Gonzalez-Castejon, J.; Smith, C.C. Optimized design of soil reinforcement layout. Géotechnique 2021. [CrossRef]

6. Alberdi-Pagola, M.; Poulsen, S.E.; Jensen, R.L.; Madsen, L. A case study of the sizing and optimization of an energy pile foundation (Rosborg, Denmark). Renew. Energy 2020, 147, 2724-2735. [CrossRef]

7. Mishra, M.; Ramana, G.V.; Maity, D. Multiverse Optimization Algorithm for Capturing the Critical Slip Surface in Slope Stability Analysis. Geotech. Geol. Eng. 2020, 38, 459-474. [CrossRef]

8. Holland, J.H. Genetic Algorithms and Adaptation. In Adaptive Control of Ill-Defined Systems; Selfridge, O.G., Rissland, E.L., Arbib, M.A., Eds.; NATO Conference Series (II Systems Science); Springer: Boston, MA, USA, 1984; Volume 16. [CrossRef]

9. Kennedy, J.; Eberhart, R. Particle Swarm Optimization. In Proceedings of the ICNN'95-International Conference on Neural Networks, Perth, Australia, 27 November-1 December 1995; Volume 4, pp. 1942-1948. [CrossRef]

10. Karaboga, D.; Basturk, B. On the performance of artificial bee colony (ABC) algorithm. Appl. Soft Comput. 2008, 8, 687-697. [CrossRef]

11. Alhashmi, A.E.; Oudah, F.; Hesham El Naggar, M. Application of binomial system-based reliability in optimizing resistance factor calibration of redundant pile groups. Comput. Geotech. 2020, 129, 103870. [CrossRef]

12. Wang, Y.; Kulhawy, F.H. Economic Design Optimization of Foundations. J. Geotech. Geoenviron. Eng. 2008, 134, 1097-1105. [CrossRef]

13. Kashani, A.R.; Gandomi, M.; Camp, C.V.; Gandomi, A. Optimum design of shallow foundation using evolutionary algorithms. Soft Comput. 2019, 24, 6809-6833. [CrossRef]

14. Seitz, K.F. Topology optimization for the design of geotechnical structures. In Proceedings of the 24th European Young Geotechnical Engineers Conference (EYGEC), Durham, UK, 10-12 September 2015; ISBN 978-0-9933836-01.

15. Shafiqul Islam, M.; Rokonuzzaman, M. Optimized design of foundations: An application of genetic algorithms. Aust. J. Civ. Eng. 2017, 16, 46-52. [CrossRef]

16. Jelusic, P.; Zlender, B. Optimal deisgn of reinforced pad foundation and strip foundation. Int. J. Geomech. 2018, 18, 04018105. [CrossRef]

17. Murlidhar, B.R.; Sinha, R.K.; Tonnizam Mohamad, E.; Sonkar, R.; Khorami, M. The effects of particle swarm optimization and genetic algorithm on ANN results in predicting pile bearing capacity. Int. J. Hydromech. 2020, 3, 69-87. [CrossRef]

18. Ravichandran, N.; Shrestha, S.; Piratla, K. Robust design and optimization procedure for piled-raft foundation to support tall wind turbine in clay and sand. Soils Found. 2018, 58, 744-755. [CrossRef]

19. Zhang, M.; Yang, J.; Ma, R.; Du, Q.; Rodriguez, D. Prediction of small-scale piles by considering lateral deflection based on Elman Neural Network-Improved Arithmetic optimizer algorithm. ISA Trans. 2021. [CrossRef] [PubMed]

20. Kinzler, S.; Grabe, J. Numerical optimization of geotechnical constructions. In Proceedings of the 17th International Conference on Soil Mechanics and Geotechnical Engineering, Alexandria, Egypt, 5-9 October 2009; Hamza, M., Shahien, M., El-Mossallamy, Y., Eds.; IOS Press: Amsterdam, The Netherlands, 2009. [CrossRef]

21. Azimi, H.; Bonakdari, H.; Ebtehaj, I.; Talesh, S.H.A.; Michelson, D.G.; Jamali, A. Evolutionary Pareto optimization of an ANFIS network for modeling scour at pile groups in clear water condition. Fuzzy Sets Syst. 2017, 319, 50-69, ISSN 0165-0114. [CrossRef]

22. Kinzler, S.; Grabe, J. Application of multi-criteria numerical optimization in geotechnical engineering. In Proceedings of the 18th International Conference on the Application of Computer Science and Mathematics in Architecture and Civil Engineering, Weimar, Germany, 7-9 July 2009.

23. Taiyari, F.; Kharghani, M.; Hajihassani, M. Optimal design of pile wall retaining system during deep excavation using swarm intelligence technique. Structures 2020, 28, 1991-1999. [CrossRef]

24. Chow, Y.K.; Thevendran, V. Optimization of pile groups. Comput. Geotech. 1987, 4, 43-58. [CrossRef]

25. Letsios, C.; Lagaros, N.D.; Papadrakakis, M. Optimum design methodologies for pile foundations in London. Case Stud. Struct. Eng. 2014, 2, 24-32. [CrossRef]

26. Kallehave, D.; Byrne, B.W.; LeBlanc Thilsted, C.; Mikkelsen, K.K. Optimization of monopiles for offshore wind turbines. Philos. Trans. R. Soc. Lond. Ser. A Math. Phys. Eng. Sci. 2015, 373, 20140100. [CrossRef] [PubMed]

27. Zhang, H.; Li, C.; Zhang, Y.; Wang, G.; Long, J.; Chen, W. Optimization on plane arrangement of stabilising piles subjected to spatial distributed lateral load in landslides with multilayer sliding masses. Eur. J. Environ. Civ. Eng. 2020. [CrossRef] 
28. Liang, X.; He, H.; Zhang, Y. Optimization design of micro-piles in landslide safety protection based on machine learning. Saf. Sci. 2019, 118, 861-867. [CrossRef]

29. Cerfontaine, B.; Knappett, J.; Brown, M.; Davidson, C.; Sharif, Y. Screw pile design optimization under tension in sand. In Proceedings of the XVII ECSMGE-2019 Icelandic Geotechnical Society, Reykjavík, Iceland, 1-6 September 2019. [CrossRef]

30. Kashani, A.R.; Gandomi, A.H. Facilitating Geotechnical Engineering Problems Using Metaheuristic Optimization Algorithms. 2019. Available online: Rocscience.com (accessed on 28 November 2021).

31. Chen, Z.Y.; Shao, C.M. Evaluation of minimum factor of safety in slope stability analysis. Can. Geotech. J. 1988, 25, 735-748. [CrossRef]

32. Chen, J.; Yin, J.H.; Lee, C.F. Upper bound limit analysis of slope stability using rigid finite elements and nonlinear programming Can. Geotech. J. 2003, 40, 742-752. [CrossRef]

33. Basson, M.S.; Ramana, G.V.; Venkataraman, R. Comparison of slope stability using smoothed particle hydrodynamics, finite element method, and limit equilibrium method. In Proceedings of the IGC-2018, Indian Geotechnical Conference, Indian Institute of Science, Bangaluru, Indian, 13-15 December 2018.

34. Raihan, T.; Khajehzadeh, M.; Eslami, M. A new hybrid algorithm for global optimization and slope stability evaluation. J. Cent. South Univ. Technol. 2013, 20, 3265-3273. [CrossRef]

35. Rowshanzamir, M.A.; Aghayarzadeh, M. Comprehensive study of geogrid-reinforced soil retaining walls with tilted face and reinforcements. Aust. J. Civ. Eng. 2015, 13, 48-63. [CrossRef]

36. Jellali, B.; Frikha, W. Constrained Particle Swarm Optimization Algorithm Applied to Slope Stability. Int. J. Geomech. 2017, 17, 06017022. [CrossRef]

37. Hajihassani, M.; Armaghani, J.D.; Kalatehjari, R. Applications of Particle Swarm Optimization in Geotechnical Engineering: A Comprehensive Review. Geotech. Geol. Eng. 2018, 36, 705-722. [CrossRef]

38. Wang, Y.; Smith, J.V.; Nazem, M. Optimization of a Slope-Stabilisation System Combining Gabion-Faced Geogrid-Reinforced Retaining Wall with Embedded Piles. KSCE J. Civ. Eng. 2021, 25, 4535-4551. [CrossRef]

39. Benayoun, F.; Boumezerane, D.; Bekkouche, S.R.; Ismail, F. Optimization of geometric parameters of soil nailing using response surface methodology. Arab. J. Geosci. 2021, 14, 1965. [CrossRef]

40. Eun-Chul, S.; Patra, C.R.; Pradhan, R. Generalized Solution procedure for Slope Stability Analysis Using Genetic Algorithm. J. KGS 2008, 24, 5-11.

41. Liao, Z.; Liao, Z. Slope stability evaluation using backpropagation neural networks and multivariate adaptive regression splines Open Geosci. 2020, 12, 1263-1273. [CrossRef]

42. Li, B.; Li, D.; Zhang, Z.; Yang, S.; Wang, F. Slope stability analysis based on quantum-behaved particle swarm optimization and least squares support vector machine. Appl. Math. Model. 2015, 39, 5253-5264. [CrossRef]

43. Javankhoshdel, S.; Cami, B.; Mafi, R.; Yacoub, T.; Bathurst, R.J. Optimization techniques in non-circular probabilistic slope stability analysis considering spatial variability. In Proceedings of the GeoEdmonton 2018, Edmonton, AB, Canada, 23-26 September 2018.

44. Pandit, K.; Sarkar, S.; Sharma, M. Chapter 11, Optimization Techniques in Slope Stability Analysis Methods. In Landslides: Theory, Practice and Modelling, Advances in Natural and Technological Hazards Research 50; Pradhan, S.P., Vishal, V., Singh, T.N., Eds.; Springer International Publishing AG: Berlin/Heidelberg, Germany, 2019. [CrossRef]

45. Cheng, Y.M. Hybrid Metaheuristic Algorithms in Geotechnical Engineering. In Metaheuristics and Optimization in Civil Engineering. Modeling and Optimization in Science and Technologies; Yang, X.S., Bekdaş, G., Nigdeli, S., Eds.; Springer: Cham, Switzerland, 2015; Volume 7. [CrossRef]

46. Mirjalili, S.; Mirjalili, S.M.; Hatamlou, A. Multi-Verse Optimizer: A nature-inspired algorithm for global optimization. Neural Comput. Appl. 2015, 27, 495-513. [CrossRef]

47. Mishra, M.; Basson, M.S.; Ramana, G.V.; Vassalo, R. Ant colony optimization for slope stability analysis applied to an embankment failure in eastern India. Int. J. Geo-Eng. 2020, 11, 3. [CrossRef]

48. Azizi, S. Application of Recent Optimization Algorithms on Slope Stability Problems. Master's Thesis, Middle East Technical University-METU, Ankara, Turkey, 2018.

49. Erzin, Y.; Cetin, T. The prediction of the critical factor of safety of homogeneous finite slopes using neural networks and multiple regressions. Comput. Geosci. 2013, 51, 305-313. [CrossRef]

50. Kalatehjari, R.; Rashid, A.S.A.; Ali, N.; Hajihassani, M. The Contribution of Particle Swarm Optimization to Three-Dimensional Slope Stability Analysis. Analysis. Sci. World J. 2014, 2014, 973093. [CrossRef]

51. Mafi, R.; Javankhoshdel, S.; Cami, B.; Jamshidi Chenari, R.; Gandomi, A.H. Surface altering optimization in slope stability analysis with non-circular failure for random limit equilibrium method. Georisk Assess. Manag. Risk Eng. Syst. Geohazards 2020, 15, 260-286. [CrossRef]

52. Reale, C.; Gavin, K.; Prendergast, L.J.; Xue, J. Multi-modal Reliability Analysis of Slope Stability. Transp. Res. Procedia 2016, 14, 2468-2476. [CrossRef]

53. Mphathiwa, N.; Cawood, F.T. Design principles for optimizing an established survey slope monitoring system. J. S. Afr. Inst. Min. Metall. 2014, 114, 463.

54. Dyson, A.P.; Tolooiyan, A. Optimization of strength reduction finite element method codes for slope stability analysis. Innov. Infrastruct. Solut. 2018, 3, 38. [CrossRef] 
55. Ter-Martirosyan, A.; Sidorov, V.; Ermoshina, L. Features of optimization of model parameters for solving geotechnical problems. MATEC Web Conf. 2018, 251, 02035. [CrossRef]

56. Gaone, F.M.; Doherty, J.P.; Gourvenec, S. An optimization strategy for evaluating modified Cam clay parameters using self-boring pressuremeter test data. Can. Geotech. J. 2019, 56, 1668-1679. [CrossRef]

57. Yin, Z.-Y.; Jin, Y.-F.; Shen, J.S.; Hicher, P.-Y. Optimization techniques for identifying soil parameters in geotechnical engineering: Comparative study and enhancement. Int. J. Numer. Anal. Methods Geomech. 2017, 42, 70-94. [CrossRef]

58. Calvello, M.; Finno, R.J. Selecting parameters to optimize in model calibration by inverse analysis. Comput. Geotech. 2004, 31, 410-424. [CrossRef]

59. Varga, R.; Žlender, B.; Jelušič, P. Multiparametric Analysis of a Gravity RetainingWall. Appl. Sci. 2021, 11, 6233. [CrossRef]

60. Mahmoudi, E.; Stepien, M.; König, M. Optimization of geotechnical surveys using a BIM-based geostatistical analysis. Smart Sustain. Built Environ. 2021, 10, 420-437. [CrossRef]

61. Boumezerane, D.; Belkacemi, S.; Zlender, B. Site Soundings Density for Geotechnical Investigation with Combined Fuzzy and Probabilistic Input Information. Geotech. Geol. Eng. 2014, 32, 547-559. [CrossRef]

62. Boumezerane, D.; Belkacemi, S.; Žlender, B. Fuzzy-sets decision-support system for geotechnical site soundings. Acta Geotech. Slov. 2011, 8, 51-63.

63. Žlender, B.; Jelušič, P.; Boumezerane, D. Planning Geotechnical Investigation Using ANFIS. Geotech. Geol. Eng. 2012, 30, 975-989. [CrossRef]

64. Chwała, M. Soil sounding location optimisation for spatially variable soil. Géotech. Lett. 2020, 10, 409-418. [CrossRef]

65. Wang, Q.; Owens, P. Reliability-based design optimization of geotechnical systems using a decoupled approach based on adaptive metamodels. Georisk Assess. Manag. Risk Eng. Syst. Geohazards 2021. [CrossRef]

66. Simpson, A.R.; Priest, S.D. The application of genetic algorithms to optimization problems in geotechnics. Comput. Geotech. 1993, 15, 1-19. [CrossRef] 